\title{
Artefato da cultura escolar e mercadoria: a escolha do livro didático de Física em análise ${ }^{1}$
}

\section{School culture artifact and market good: an analysis about choosing physics textbooks}

\author{
Alisson Antonio Martins* \\ Nilson Marcos Dias Garcia**
}

\begin{abstract}
RESUMO
Apresentam-se resultados de pesquisa qualitativa cujo objetivo foi identificar de que modo os eixos analíticos da cultura escolar, da produção cultural e do mercado estão articulados num processo de escolha e apropriação de livros didáticos por professores de Física, brasileiros e portugueses, que atuam na educação básica. Dividida em duas etapas, a pesquisa contou com aplicação de questionários e realização de entrevistas semiestruturadas, sendo as informações obtidas analisadas com base nos procedimentos da Análise de Conteúdo. Os resultados indicaram que os professores escolhem seus livros didáticos a partir de uma combinação desses eixos. Desse modo, a escolha constitui-se em um processo complexo de produção de sentidos e significados, construída ao longo da atividade docente e culminando na indicação de um livro didático que melhor representa as expectativas dos professores com relação a esses eixos e em face do contexto social, econômico e cultural.

Palavras-chave: Livro didático de Física. Escolha de livro didático. Cultura escolar. Produção cultural. Mercadoria.
\end{abstract}

1 O primeiro autor contou com bolsa Capes/Reuni e Capes/PDSE durante seu doutorado, período em que foi realizada a pesquisa.

* Universidade Tecnológica Federal do Paraná. Departamento Acadêmico de Física. Programa de Pós-Graduação em Formação Científica, Educacional e Tecnológica. Curitiba, Paraná, Brasil. E-mail: amartins@utfpr.edu.br. https://orcid.org/0000-0002-4431-2247.

** Universidade Tecnológica Federal do Paraná. Programa de Pós-Graduação em Tecnologia e Sociedade. Universidade Federal do Paraná. Programa de Pós-Graduação em Educação. Curitiba, Paraná, Brasil. E-mail: nilson@utfpr.edu.br. https://orcid.org/0000-0002-3242-994X. 


\begin{abstract}
We present the results of a qualitative research which aimed at identifying how the analytical axes of school culture, cultural production and of the market are connected during the selection and usage processes of choosing and using physics textbooks performed by Brazilian and Portuguese teachers working with Basic Education. Divided into two stages, the research was carried out by applying questionnaires and conducting semi-structured interviews, and the information gathered was analyzed based on Content Analysis procedures. The results indicated that the teachers choose their textbooks based on a combination of these axes. The selection is performed through a complex production process of senses and meanings, developed throughout teaching activities and culminating on the indication of one textbook which best matches the expectations of teachers regarding these aspects in connection to social, economic and cultural contexts.
\end{abstract}

Keywords: Physics textbooks. Textbooks choice. School culture. Cultural production. Market goods.

\title{
Introdução
}

A política de distribuição de livros didáticos aos alunos do ensino médio das escolas públicas brasileiras, por meio do Programa Nacional do Livro Didático (PNLD), tem oportunizado um olhar mais amplo sobre a sua produção em função da universalidade do acesso às obras didáticas neste nível de ensino. Esta situação trouxe novos desafios às pesquisas educacionais devido à renovação das problemáticas, pois as tensões entre as normas, oriundas dos órgãos responsáveis pelas políticas educacionais relativas às publicações didáticas, e a realidade escolar em que se inserem alunos e professores receberam novos matizes.

Esse renovado interesse das pesquisas se expressa pelo aumento de publicações em periódicos e em eventos científicos, bem como pelo ampliado número de teses e dissertações produzidas em Programas de Pós-Graduação em Educação e em Ensino. Este aumento quantitativo tem sido acompanhado de uma alteração de natureza qualitativa das pesquisas, uma vez que são apresentadas novas problemáticas, com a possibilidade de realização de estudos com outro grau de objetividade, que podem ser analisados tomando como base a normatização da produção didática destinada à educação básica estabelecida pelos editais do PNLD. 
Em função dessas condições, faz-se necessário aprofundar as análises relativas aos livros didáticos tomando como base o que já havia se estabelecido enquanto matriz teórica na temática. Dentre outros, os trabalhos de Barra e Lorenz (1986), Bittencourt (2004), Choppin (2004), Garcia (2016), Garcia (2012), Garcia (2009), Lorenz (2010), Megid Neto e Fracalanza (2006), Reiris (2005) e Wuo (2000) estabelecem um quadro das pesquisas sobre os livros didáticos.

No específico do ensino de Ciências e de Física, a expansão da pósgraduação em Educação e em Ensino estimulou o aumento das pesquisas sobre a temática. Autores como Leite, Garcia e Rocha (2017) e Souza e Garcia (2017) apontam que as principais tendências de pesquisa sobre os livros didáticos têm se referido à correção conceitual dos conteúdos e às metodologias e demais aspectos a eles internos. Mantém-se, porém, uma carência daquelas sobre as razões que levaram os livros a se constituírem do modo como são conhecidos, com poucas reflexões sobre o seu uso ou sobre sua escolha, razão da importância desses fatores estabelecerem-se como foco de pesquisa sobre os livros didáticos.

Entendidos como elementos da cultura escolar, produtos culturais e mercadorias, seu estudo deve ser desenvolvido na imbricação entre esses três eixos, possibilitando lançar luzes sobre os aspectos que os professores de Física consideram quando escolhem um livro didático e compreender as diferenças de ordem educacional, cultural e econômica que se expressam em relação à escolha de obras didáticas.

Assumindo as diferenças que emergem de distintas realidades educacionais, este artigo apresenta alguns dos resultados de uma pesquisa desenvolvida com professores de Física da educação básica atuantes no Brasil e em Portugal, visando a identificar de que modo a cultura escolar, a produção cultural e o mercado, enquanto eixos analíticos, articulam-se num processo de escolha de livros didáticos por estes professores.

\section{Livros didáticos: elementos da cultura escolar}

De acordo com Choppin (2004), os livros didáticos desempenham quatro funções no contexto da educação escolar: referencial, instrumental, ideológica e cultural e documental.

A função referencial expressa a noção de que os livros didáticos são suportes privilegiados dos conteúdos, de conhecimentos, de técnicas ou habilidades, estando relacionados àquilo que é considerado importante de se transmitir no interior de um determinado grupo social. A função instrumental 
pode ser compreendia pelo fato de que "o livro didático põe em prática métodos de aprendizagem, propõe exercícios ou atividades" (p. 553), contribuindo para processos de memorização de conhecimentos, aquisição de competências, apropriação de habilidades. A terceira função, ideológica e cultural, apontada como sendo a mais antiga, está relacionada ao fato de o livro didático constituir-se num importante elemento para a configuração e confirmação da "língua, da cultura e dos valores das classes dirigentes" (p. 553). Nesse sentido, os livros didáticos possuem um importante valor simbólico no processo de aculturação, explícito ou implícito, das novas gerações. Por fim, a função documental está circunscrita aos ambientes em que se privilegia a iniciativa e a autonomia dos alunos, demandando sua participação ativa, além de uma adequada capacitação docente centrada nesse foco. Nessa função, a mais recente de todas, os livros didáticos possibilitam o fornecimento de "um conjunto de documentos, textuais ou icônicos, cuja observação ou confrontação podem vir a desenvolver o espírito crítico do aluno" (p. 553).

Essas funções permitem estabelecer relações entre os livros didáticos e o contexto educacional, em razão da existência das disciplinas escolares que, de acordo com Chervel (1990), não se constituem em uma simples vulgarização dos conhecimentos das ciências de referência, constituindo-se segundo uma lógica própria, vinculada à existência da instituição escolar, culminando no que Lopes (1999) identifica como sendo conhecimento escolar.

Essas duas noções, disciplina e conhecimento escolar, complementares, vinculam-se ao conceito de cultura escolar que, para Forquin (1993), refere-se a um conjunto de "conteúdos cognitivos e simbólicos que, selecionados, organizados, 'normatizados', 'rotinizados' sob o efeito dos imperativos de didatização, constituem habitualmente o objeto de uma transmissão deliberada no contexto das escolas" (p.167). Dentre as distintas propriedades inerentes aos livros estão aquelas que se referem à seleção e à organização curricular dos conhecimentos escolares de uma determinada disciplina, com vistas a atender às necessidades educacionais sendo, portanto, elementos da cultura escolar.

\section{Livros didáticos: produtos culturais e mercadorias}

Considerando-se haver uma interdependência entre o contexto educacional e o social mais amplo, é possível compreender que os livros didáticos guardam relação com a estrutura social em duas dimensões específicas. Por um lado, eles são produtos culturais (BITTENCOURT, 2004), produzidos e consumi- 
dos de determinados modos, por determinados grupos sociais. Por outro, são mercadorias (APPLE, 1995, MUNAKATA, 2012, CASSIANO, 2013), pois a sua produção e o seu consumo se dão em uma sociedade baseada nas trocas realizadas no mercado.

As preocupações sobre as relações entre produção cultural e mercantil iniciaram-se com os estudos realizados no âmbito da Escola de Frankfurt, cujas reflexões pioneiras de Adorno e Horkheimer (1991) lançaram as bases para a construção da Teoria Crítica da Sociedade. Nesta se destaca a noção de "Indústria Cultural", cujo centro seria a produção planejada de certos produtos culturais associados a uma determinada forma de consumo.

Nessa perspectiva, os livros didáticos poderiam ser interpretados como produtos culturais que imprimiriam sobre seu público um determinado modo de consumo. No caso do PNLD, isso se expressaria por meio de uma disputa entre o Estado brasileiro e as empresas editoras, ambos intervindo sobre a produção didática de modo a manifestar seus interesses precípuos, pois, de acordo com Rosa e Megid Neto (2016, p. 1352), essas intervenções "ocorrem pelo fato do LD necessitar se adequar à demanda dos professores e escolas, para uma chance relativamente maior de vendagem, tarefa que extrapola o papel e o trabalho do autor da obra". Assim, para Rosa e Megid Neto (2016), uma melhor inserção dos livros didáticos no mercado representaria uma quebra da autonomia dos autores, enquanto uma das possíveis manifestações da Indústria Cultural.

Por outro lado, num sentido teórico, é necessário compreender o polo do consumo dos livros didáticos, em um contraponto dialético ao polo da produção. Ou seja, os livros didáticos poderiam cumprir outras funções sociais, não antevistas em sua produção, devido à complexidade das relações que com eles se estabelecem, pois, embora com destinação social específica para a educação escolar, eles podem ser compreendidos de modos diferenciados, a partir das características de sua apropriação em contextos sociais distintos.

Nesse sentido, de acordo com Bourdieu (2009), o modo de apropriação dos produtos culturais relaciona-se às posições, situações e disposições expressas pelos agentes na estrutura social, conferindo aos livros didáticos distintos sentidos e significados, dependendo da localização dos agentes nessa estrutura. Ao lado do consumo, a produção de livros didáticos, enquanto uma das esferas da produção cultural, por sua vez, encontra-se subordinada às relações mercantis nas quais as editoras guardam suas expectativas. Entretanto, apesar da forma assumida pela produção, os sentidos e os significados atribuídos aos livros por alunos e professores dependerão dos recursos por eles mobilizados. Esses recursos não se restringem a uma questão econômica, embora esta seja fundamental no caso da aquisição de livros, mas envolvem diversos capitais, como, por exemplo, os 
capitais culturais, sociais e simbólicos, referentes às apropriações de distintos produtos culturais (BOURDIEU, 2009).

Esses aspectos evidenciam as complexidades que emergem do estudo sobre os livros didáticos, dada sua inserção em uma sociedade produtora de mercadorias. Deste modo, Apple (1995) e Munakata (2012) apontam que os livros didáticos podem ser compreendidos como mercadorias que, conforme a teoria do valor-trabalho de Marx (2010), possuem uma dupla natureza, isto é, por um lado, constituem um valor de uso, uma utilidade, e, por outro, um valor de troca, um valor, isto é, carregam consigo um tempo de trabalho social que, no processo de troca, corresponderá a outros tempos de trabalho empregados na produção.

A análise do valor de uso dos livros didáticos permite compreender que os agentes que guardam relações com o contexto educacional criam certas expectativas em relação a eles, mobilizando distintos recursos para deles se apropriarem, fazendo com que esses livros sejam portadores de significados que superam sua vinculação ao espaço escolar.

Enquanto campo da produção cultural, a produção de livros didáticos tornou-se mais complexa ao longo dos anos, principalmente no contexto dos Editais Públicos do PNLD, nos quais as empresas editoras investem nas obras visando a atender expectativas de lucro com a venda dos livros didáticos selecionados, levando-se em conta, centralmente, o valor que pode ser realizado com a troca desses livros.

Mantém-se, neste contexto, uma relação contraditória entre os agentes culturais e os profissionais de mercado, com os primeiros ocupando posições nas quais se manifestam os interesses sobre os conteúdos da produção cultural e os segundos ocupando posições nas quais as formas assumidas pelos produtos culturais representam benefícios no campo econômico.

Apesar dessa contradição, mas também por conta dela, a cadeia produtiva dos livros didáticos tornou-se bastante complexa ao logo dos últimos anos, envolvendo um sem número de profissionais na sua produção, com destaque para os agentes editoriais que cumprem um papel central tanto da seleção de autores e de obras que possuem potencial de mercado, quanto na indução daquilo que se configurará enquanto conteúdo a ser expresso por tais obras.

Essas questões podem ser analisadas à luz das relações estabelecidas entre campo da produção cultural e campo econômico. Assim, de acordo com Williams (2000), a produção cultural vincula-se à ação de "profissionais empresariais", isto é, os editores que fazem o papel de intermediários produtivos entre os autores em potencial e as expectativas das empresas editoras. No contexto do PNLD, tais expectativas referem-se à aprovação das coleções didáticas nos editais públicos 
do programa, cabendo aos editores, por conseguinte, criar condições para que os seus livros didáticos apresentem melhores condições para essa aprovação.

Dentre os principais agentes envolvidos na produção e uso dos livros didáticos, têm-se os autores, que sistematizam o que os professores irão desenvolver em suas aulas. Assim, de forma dicotômica, de um lado, têm-se os que pesquisam e produzem conhecimento e, do outro, os que vão ensinar, colocando, conforme Garcia (2012), “em margens opostas os 'professores pesquisadores' e os 'professores não pesquisadores'- estes últimos aqueles que são preparados 'apenas para ensinar'” (p. 253), gerando uma desigual distribuição de capitais que tenderá a levar os agentes, que ocupam posições determinadas na estrutura social, com certas disposições incorporadas, a uma apropriação desigual dos mais distintos elementos dessa estrutura.

\section{Procedimentos metodológicos da pesquisa de campo}

Caracterizada como uma pesquisa qualitativa, esta investigação teve como objetivo identificar de que modo os eixos analíticos cultura escolar, produção cultural e produção mercantil articulam-se nas escolhas dos livros didáticos de Física realizadas por professores que atuam na educação básica no Brasil e em Portugal, possibilidade que foi aberta com a realização de parte do doutorado de um dos autores na Universidade de Lisboa. ${ }^{2}$

Os professores participantes foram selecionados por terem passado por um processo formativo na Licenciatura em Física e terem em comum a participação em atividades de extensão e em eventos em que são discutidas questões relativas à pesquisa e ao ensino de Física. Assim, foram convidados professores que participaram de uma edição da Escola de Professores no CERN em Língua Portuguesa $^{3}$, evento que ocorreu no Centro Europeu de Pesquisas Nucleares CERN -, em Genebra, na Suíça, constituindo-se, portanto, não numa amostra estatística, mas numa amostra intencional.

2 A pesquisa foi desenvolvida no âmbito do Programa de Pós-Graduação em Educação da UFPR, com parte dela realizada durante o Doutorado-sanduíche (PDSE) no Instituto de Educação da Universidade de Lisboa, Portugal, sob supervisão da Prof. ${ }^{a}$ Dr. ${ }^{a}$ Mónica Luísa Mendes Baptista, a quem agradecemos pela valiosa contribuição.

3 Esta Escola, realizada em Genebra, Suíça, é organizada pelo CERN, em parceria com o Laboratório de Instrumentação e Física Experimental de Partículas (LIP), de Portugal. Os professores brasileiros participantes foram selecionados por meio de um processo coordenado pela Sociedade Brasileira de Física, e os que atuavam em escolas públicas foram financiados pela Capes. 
Os dados foram obtidos por meio de dois instrumentos. Inicialmente foi aplicado um questionário aos professores e depois foram realizadas entrevistas semiestruturadas com alguns desses professores que se dispuseram a participar.

O questionário foi constituído por blocos que visavam ao levantamento de informações que possibilitassem, por um lado, caracterizar os participantes da investigação quanto à sua identificação pessoal, aos aspectos formativos e sua atuação profissional e, por outro, caracterizar os aspectos relativos à escolha de livros didáticos de Física.

Ele foi elaborado em duas versões equivalentes, necessárias por pequenas variações linguísticas. Diferiam por duas questões relacionadas ao PNLD, que figuraram apenas no que foi aplicado aos professores brasileiros. O questionário apresentava cinco questões abertas referentes ao levantamento de informações pessoais e formativas dos participantes da pesquisa. As demais questões abertas acompanhavam as questões fechadas com o intuito de possibilitar aos participantes o apontamento de aspectos que não tivessem sido contemplados. Como eixo central se estabeleceu um conjunto de proposições relativas aos fatores que poderiam motivar a escolha do livro didático de Física, elaboradas a partir de estudo teórico e do diálogo com os resultados das pesquisas acadêmicas na temática.

A entrevista, semiestruturada, orientou-se segundo um roteiro que explorava a interpretação dos respondentes relativas aos livros didáticos de Física como elementos da cultura escolar, produtos culturais e mercadorias. Foram gravadas, transcritas, organizadas e, na sequência, sistematizadas em função dos eixos analíticos.

\section{Resultados e análises}

Para a interpretação das informações foram adotados os procedimentos da análise de conteúdo propostos por Bardin (1994). Enquanto percurso metodológico, a exploração do material ocorreu a partir da leitura intensiva das informações fornecidas pelos participantes. A seguir, foram codificados os extratos que guardavam relação com as categorizações formuladas. Por fim, os resultados foram elaborados a partir de inferências e da interpretação, norteadas pelos pressupostos teóricos apresentados. 


\section{Caracterização dos participantes}

O questionário foi enviado por e-mail aos 30 professores brasileiros e a 33 professores portugueses que iriam participar da Escola para professores de Física em Língua Portuguesa do CERN, tendo retornado 17 questionários de professores brasileiros e 14 de portugueses, aos quais foram designados códigos para manter as suas privacidades e o anonimato. Assim, os professores brasileiros que responderam ao questionário foram codificados de B01 a B17 e os portugueses de $\mathrm{P} 01$ a $\mathrm{P} 14$. Os mesmos códigos foram utilizados para a identificação dos sujeitos que concederam entrevistas.

Dos 17 professores brasileiros, cinco eram do sexo feminino e 12 do sexo masculino. Quanto à formação acadêmica, apenas um não era formado em Física, disciplina na qual os demais 17 possuíam graduação. Em relação à pós-graduação, seis possuem especialização, quatro eram mestres, três estavam cursando o mestrado e três o doutorado.

Dos 14 professores portugueses, sete eram do sexo feminino e sete do sexo masculino. Dois possuíam graduação em Física, cinco em Física-Química, os demais tinham graduação em Química, Engenharia Química ou Bioquímica. Os professores que não possuíam graduação em Física ingressaram na carreira docente e, após, desenvolveram a Profissionalização em Serviço, uma especialização que os habilitou a atuar nessa disciplina. Sobre a pós-graduação, dois professores indicaram que não cursaram nenhum curso neste nível, três cursavam o mestrado, sete já o haviam concluído e um cursava o doutorado.

Considerando o grupo como um todo, percebeu-se uma homogeneidade formativa e profissional. Dos 31 professores, 23 atuavam apenas em escolas públicas, sete em escola pública e em escola particular, quatro deles com mais tempo na escola pública e três na escola particular e apenas um atuava exclusivamente em escola particular. Quanto ao nível de atuação, 25 trabalhavam predominantemente na escola secundária, quatro no ensino fundamental e dois no ensino técnico secundário. Todos, porém, possuíam experiência no nível secundário. Em relação ao tempo de atuação profissional, a maioria atuava há mais de 11 anos e apenas sete professores atuavam há menos de 10 anos.

Os professores também foram convidados a conceder uma entrevista, que foram realizadas nos intervalos das atividades da Escola de professores no CERN em Língua Portuguesa, nas próprias dependências do CERN, em Genebra. De tempo variável, foram realizadas com 15 professores, oito brasileiros e sete portugueses. 


\section{O processo da escolha de livros didáticos}

A análise das informações obtidas por meio dos instrumentos de pesquisa permitiu observar elementos de aproximação e de afastamento acerca dos aspectos considerados para a escolha dos livros didáticos de Física pelos dois grupos de professores participantes.

Em linhas gerais, os professores brasileiros e portugueses apontaram que a escolha ocorre de modo coletivo, havendo, entretanto, distinções no coletivo participante da escolha. Os professores brasileiros relataram que escolhemos livros com a participação apenas de outros professores que também atuam no ensino médio. Os professores portugueses, por sua vez, indicaram que o processo coletivo de escolha envolve também professores de outros níveis de ensino. Em função desse processo, diferentemente dos professores brasileiros, que analisam no contexto apenas do nível em que atuam (ensino médio), os professores portugueses, por envolverem na escolha professores de distintos níveis (básico e secundário), criam condições para que se possa projetar caminhos a serem seguidos pelos estudantes no decorrer do percurso escolar. Essas posições são exemplificadas com os seguintes extratos ${ }^{4}$ :

É uma escolha coletiva, ... de todos os professores que atuam na área, que militam nesta área. (...) a gente tentou obedecer a isso até mais ou menos que surgiu um consenso, né, de todos os professores. (...) não vou dizer que foi, é, unânime a escolha. Sempre tem um professor, não, que queria determinado livro, pôs os seus argumentos e tal, mas a maioria acabou escolhendo determinado livro (...) (B14E $)$

Normalmente o processo é feito em grupo. (...) há vários professores a dar a mesma disciplina, por norma, quem trabalhou mais com determinado ano de escolaridade, quando chega à altura de escolher um manual prá esse ano de escolaridade, por norma, os professores que trabalharam com esse manual, desse ano de escolaridade, nos últimos anos são os que conhecem melhor o manual, são os que sabem dizer se há muitas

4 Nas transcrições dos extratos foram respeitadas expressões características da nacionalidade dos professores, assim como eventuais simplificações ou expressões que podem não respeitar a norma culta da língua portuguesa.

$5 \mathrm{O}$ código entre parênteses ao final do excerto indica se o professor é brasileiro (B) ou português $(\mathrm{P})$, acompanhando-se da numeração atribuída ao sujeito e da fonte da informação: questionário (Q) ou entrevista (E). Nesse caso, a informação foi obtida na entrevista concedida pelo professor brasileiro B14. 
ou poucas gralhas ${ }^{6}$ no manual, que normalmente é uma constante, principalmente se os manuais são recentes, são eles que podem dizer se os exercícios que aparecem no manual são mais ou menos interessantes (...) digamos que esses dois ou três professores terão uma opinião mais, mais consolidada sobre a escolha do manual a seguir (...) (P09E)

Esses posicionamentos ilustram uma característica que pode ser interpretada em função das distintas condições de trabalho a que estariam submetidos esses dois grupos de professores. Por um lado, a maioria dos professores brasileiros apontou que as condições gerais de trabalho, tais como número de alunos por turma, número de turmas e número de escolas em que atuam interferem e/ou influenciam a escolha de seus livros didáticos. Por outro, os professores portugueses apontaram que essas questões não interferem em suas escolhas, ressaltando uma situação em que a possibilidade de se trabalhar em apenas uma escola, com carga horária maior para cada turma, permite um acompanhamento mais intensivo dos alunos, possibilitando escolher um livro mais adequado à transição entre os níveis de ensino.

\section{Escolha de livros didáticos de Física enquanto elementos da cultura escolar}

A consideração de aspectos que, notadamente, relacionam-se ao significado que o livro didático possui para o processo de ensino-aprendizagem da Física, indica que a consideração do livro didático de Física como um elemento da cultura escolar predomina frente aos demais eixos considerados neste estudo.

Outro aspecto que indica que a cultura escolar é predominante para a escolha dos livros de Física se revelou por meio das considerações dos professores que procuram livros que estejam de acordo com as orientações curriculares oficiais vigentes em cada país. Sobre isso, destacam-se algumas diferenças em relação às orientações curriculares de Brasil e Portugal, impactando, assim, sobre o processo de escolha dos livros didáticos de Física. Enquanto em Portugal o currículo oficial é unificado nacionalmente, e seus professores percebem que os livros didáticos de Física guardam grande homogeneidade a ele, no Brasil, por

6 "Erro que, por lapso, ficou num texto escrito". Fonte: Dicionário Priberam da Língua Portuguesa Online. 
existirem diretrizes e parâmetros curriculares nacionais, mas também orientações curriculares estaduais, essa homogeneidade não é verificada de modo satisfatório, uma vez que esses livros têm a sua produção pautada, hegemonicamente, nos pressupostos das orientações nacionais em detrimento das estaduais. $\mathrm{O}$ posicionamento a seguir exemplifica esse tipo de dificuldade:

Outra coisa que, na escolha do livro que eu, não me agrada, que, de acordo com o PCN, e, lá [no Estado] nós temos também o [currículo do estado], que (...) nós temos que seguir. A escola exige que tenha que seguir. O que acontece? No [currículo do estado] eles colocam conteúdos prá ser ministrado no primeiro ano, conteúdos que eu só vou encontrar no livro do terceiro ano. (B04E)

Ainda sobre a noção de cultura escolar, os professores consideraram a adequação das obras aos processos seletivos de acesso ao ensino superior como um importante aspecto para a sua escolha, não obstante as diferenças entre esses processos, consonantes às orientações curriculares de cada país.

Inferiu-se ainda que, em sua maioria, os participantes consideram que os livros didáticos de Física cumprem funções instrumentais e referenciais (CHOPPIN, 2004), destacando-se que a sua escolha ocorre devido à presença de atividades experimentais e de listas de exercícios.

\section{Escolha de livros didáticos Física enquanto produtos culturais}

A presença de elementos diferenciados nos livros didáticos de Física contribui para que eles sejam considerados como produtos culturais. Ao se extrapolar, por exemplo, um uso "convencional", pautado na análise de exemplos ou na resolução de exercícios, a partir da atribuição de um significado especial à leitura, ao cuidado com o cotidiano dos alunos, os participantes têm em vista a inserção desses livros em um processo cultural mais amplo.

De modo objetivo, principalmente para os professores brasileiros, a autoria dos livros didáticos de Física contribui para que sejam escolhidos determinados livros em detrimento de outros, demonstrando que a autoria, enquanto uma característica da produção cultural, pode se constituir em um elemento importante para a escolha. Assim, alguns deles consideraram que conhecer os autores das obras 
e suas produções anteriores contribui para a escolha dos livros, como se percebe nas seguintes posições, com grifos nossos para ressaltar essa interpretação:

\section{(...) conhecendo uma obra anterior do autor causa uma maior inclinação na hora da escolha, tal qual a escolha de diretor de cinema. (B09Q)}

Esses posicionamentos indicam a importância de se escolher um livro norteando-se pelo conhecimento dos autores e de suas produções. O reconhecimento de autores que produzem livros didáticos de certo tipo, com certas características, motiva a escolha pelos professores. Entretanto esse posicionamento pode apresentar riscos se a escolha for feita centralmente pelo nome do autor do livro, pois pode ocorrer incompatibilidade entre o "nível do livro didático" e o "nível dos alunos".

Entre os professores portugueses não foram encontrados posicionamentos semelhantes. Embora alguns deles apontem que as relações com a realidade, o cuidado com o nível etário e a adequação da linguagem constituam-se em elementos a serem considerados nos processos de escolha, não houve manifestação indicativa de que os autores dos livros não cumprissem essas demandas, tal como foi verificado para os professores brasileiros.

Essa diferenciação deve-se ao fato de haver poucas diferenças culturais entre as regiões de Portugal, o que não se verifica no Brasil, país de dimensões continentais e cuja diversidade cultural transforma projetos de proposições culturais homogêneas em um grande desafio para os autores de livros didáticos e para as instâncias oficiais.

Assim, a formação acadêmica dos autores de livros didáticos também pode ser compreendida desde uma perspectiva cultural. Os professores brasileiros, sem ressonância entre os portugueses, apresentaram posições acerca de como julgam dever ser a formação acadêmica dos autores. Para alguns professores os autores deveriam possuir formação acadêmica em Física, para outros, estes deveriam ser formados no campo da Educação:

A maioria dos autores não tem formação na área da Educação. Esse tipo de autor não tem a menor noção do que está fazendo. Na maioria das vezes reproduz um material conforme suas experiências como estudante. (...) Os critérios têm que melhorar, mas a qualidade dos livros também. Os editais [do PNLD] deveriam restringir a autores com formação na área da Educação. (B12Q) 
[o professor não se identifica com] Livros escritos por autores que não são físicos, pois quem deve escrever livros de Física são pessoas que possuem conhecimentos suficientes para fazê-los. (B16Q)

Embora a formação acadêmica dos autores não seja um impeditivo à elaboração de livros didáticos, pois estes são norteados pelas orientações curriculares oficiais e pelos objetivos do ensino de Física, esses posicionamentos expressam uma preocupação relativa à adequação das obras, tanto em relação à ciência de referência, quanto à didática da disciplina. Essas preocupações vinculam-se à produção cultural uma vez que se considera que os resultados de determinadas atividades devem ser compreendidos à luz das práticas dos sujeitos por elas responsáveis.

Assim, diferentemente de uma produção cultural presumidamente desinteressada, a produção de livros didáticos deve reconhecer seu caráter dirigido, isto é, destinado ao contexto da educação escolar. Em linhas gerais, os livros didáticos de Física não fogem a este padrão.

\section{Escolha de livros didáticos de Física enquanto mercadorias}

Considerar os livros didáticos como mercadorias implica identificar de que modo os sujeitos os acessam, ou seja, pela compra direta no mercado, pela compra com um apoio financeiro público ou pelo acesso gratuito em programas governamentais. Para a maioria dos professores brasileiros atuantes em escolas públicas, o acesso aos livros ocorre pelo PNLD e, para os das escolas particulares, pela compra no mercado. Entre os professores portugueses das redes pública e particular, o acesso ocorre pela compra no mercado, porém, para alunos carentes, excepcionalmente, há a possibilidade de um subsídio do governo português.

Embora se pudesse supor que o acesso gratuito aos livros didáticos encontrasse concordância consensual entre os professores brasileiros, essa situação não é necessariamente verdadeira. Neste sentido, alguns posicionamentos expressaram uma preocupação relativa à desvalorização dos livros didáticos no contexto escolar.

Sobre a possibilidade de distribuição gratuita dos livros, os professores portugueses consideraram que esta questão poderia ser interessante, embora apontassem que, no horizonte do contexto econômico pelo qual o país passava, isso não estaria dado: 
Seria bom, mas eu não acredito que neste momento Portugal tenha recursos financeiros prá fazer uma coisa dessas. O que nós temos (...), é aqueles alunos que já têm ajuda, portanto, que têm rendimentos menores, esses sim têm os manuais, ou gratuitos, ou então a um preço mais baixo (...) há a assistência social na escola, assistência escolar. Mas é bom, uma margem de alunos mínima com os recursos mais baixos, a grande maioria dos alunos tem que comprar os manuais. (P05E)

Sobre o acesso pago aos livros, os professores brasileiros não ofereceram muitas informações, pois, em sua maioria, trabalham em escolas públicas, nas quais seus alunos os recebem por meio do PNLD. Entretanto alguns deles se declararam incomodados com o "desperdício enorme porque os livros são do Governo Federal e sofremos pressões para o utilizarmos apenas como 'complemento' do material elaborado pelo Estado" (B08Q), assim como pela variação do preço do livro de um ano para o outro (B17Q). Outros, mencionando o preço dos livros, indicaram que os alunos com menos condições financeiras não têm acesso, por serem caros, revelando preocupações relativas à classe social dos alunos.

Para os professores portugueses, a influência do preço sobre a escolha é variável, indo de posições que indicam haver uma influência ou que oscilam entre poder influenciar ou não. Estas oscilações se dão em função dos materiais complementares aos livros, das condições socioeconômicas dos alunos e da conjuntura econômica nacional. Sobre os materiais complementares, eles apontam que estes tendem a encarecer os livros, passando a ser um aspecto relevante para a escolha.

O preço dos manuais, com recursos, cadernos laboratoriais elou de exercicios, e CD/DVD (opcional), tornam os designados "Projetos Pedagógicos" demasiado caros, atendendo que esta disciplina requer igual dose para a Quimica. ${ }^{7}$ (P08Q)

Em relação às condições socioeconômicas dos alunos, os professores portugueses apontam que o preço dos livros configura-se como um aspecto importante para a escolha:

7 Em Portugal, entre o $7 .^{\circ}$ ano do $3 .^{\circ}$ ciclo do ensino básico e o $11^{\circ}$ ano do ensino secundário, o ensino de Física dá-se em concomitância com a Química, em uma disciplina escolar denominada Física-Química. 
Nomeadamente, tem escolas como a minha, de uma população economicamente desfavorecida, quando há manuais em dúvida, a confrontarem-se uns com os outros, nós escolhemos o mais barato. (P07E)

Por fim, no que diz respeito à conjuntura econômica portuguesa, alguns professores apontaram que o preço dos livros é um fator importante para escolha.

Ainda que isso não seja a questão fulcral, porque nós não escolhemos manuais há uns quatro anos, e nessa altura a situação não estava tão má como agora, eu penso que, agora, cada vez mais isso vai ser uma questão a colocar [...] nós vamos escolher este manual porque, além de ser bom cientificamente, ele é mais barato que aquele, e não pesa tanto no orçamento familiar. [...] Se estivermos em dúvida entre dois manuais que são muito próximos em termos de rigor, pesarmos para o manual que terá menos peso econômico a nível familiar. (P06E)

Estes aspectos permitem discutir o eixo mercadológico dos livros didáticos. A percepção de que um objeto se constitui em uma mercadoria articula, por si, a dupla natureza econômica deste objeto, entre o seu valor de uso e o seu valor de troca, denominado simplesmente valor. O preço não é idêntico a este valor, mas se constitui em sua expressão nas trocas que ocorrem no mercado. Assim, a consideração dos preços no processo de escolha de livros revela uma preocupação acerca do eixo mercadológico que supera a consideração de sua destinação escolar, articulando outros elementos, como as condições socioeconômicas dos alunos e a conjuntura econômica do país.

\section{Considerações finais}

Alguns dos elementos que contribuem para que os professores escolham e se apropriem de seus livros didáticos - listas de exercícios e atividades experimentais, as relações com as orientações curriculares e com os processos seletivos, a autoria, a organização dos conteúdos de ensino, o acesso aos livros e o papel das editoras - foram identificados e permitiram algumas interpretações e conclusões à luz dos eixos analíticos considerados: o livro como elemento da cultura escolar, como produto cultural e como mercadoria. 
Concluiu-se, inicialmente, que a escolha e apropriação dos livros didáticos de Física pelos professores ocorreram, prioritariamente, considerando-os como elementos da cultura escolar, secundadas pelas influências exercidas pelos outros eixos, expressas em diversos níveis pelos agentes em função dos contextos culturais, econômicos e sociais em que se inserem. Considerando a seleção cultural promovida pelos livros em busca do atendimento de demandas diferenciadas - o valor de uso na escola e o valor de troca no mercado - sua escolha e apropriação variarão em função das especificidades regionais e da medida em que cada uma delas se expressa, numa articulação entre situações e condições específicas e o todo da sociedade.

Uma segunda conclusão que releva o fato de a escolha desses livros expressar-se prioritariamente a partir dos elementos da cultura escolar indica que, para os professores, o seu valor de uso sobrepõe-se ao seu valor de troca, pois eles têm em vista as suas finalidades didáticas, desconsiderando, sob certa medida, a pouca diversificação das obras. Em função disso, esses agentes mobilizam distintos recursos no sentido de se apropriarem dos livros didáticos de modo específico, como elementos da cultura escolar. Isso se evidencia nas considerações relativas à adequação dos livros aos contextos culturais e sociais e é reafirmada pela preocupação com a linguagem dos livros, que revela que os professores compreendem que os livros serão apropriados de forma sui generis e determinada.

Sobre a questão da adaptação das obras às propostas pedagógicas das escolas, os professores brasileiros buscam atender anseios concernentes ao nível local, por meio da busca de livros adequados aos currículos estaduais e aos processos seletivos. Em função de necessidades por eles antevistas, os livros cumprirão certas funções, estando mais ou menos adequados àquilo que se apresenta em termos de expectativas ou de prescrições. Confirma essa interpretação o fato de que essas questões não foram problematizadas do mesmo modo pelos professores portugueses, pois os seus livros estariam mais adequados apenas às prescrições oficiais. Neste sentido, uma terceira conclusão revela que os professores se identificam com os livros na medida em que estes se atendem às necessidades curriculares da disciplina.

Nos dois países pesquisados, uma crescente homogeneização e padronização da produção didática tem implicado nos critérios de escolha e sobre os modos de apropriação dos livros pelos professores, levando as editoras a buscarem alternativas para que suas obras sejam vendidas ou compradas. No Brasil, essas alternativas têm passado pela autoria dos livros, com as editoras apostando em autores consagrados e já conhecidos pelos professores. Em Portugal, por sua vez, as editoras têm procurado incluir elementos extras aos livros, o que contribui para que os professores os escolham pelos aspectos diferenciais que 
esses trazem. Portanto, uma maior padronização da produção didática resulta numa concentração de investimentos em livros cujas autorias e características diferenciais ampliem as possibilidades de retorno financeiro para as editoras, acentuando-se, desse modo, o seu caráter mercadológico.

Sobre a influência do eixo mercadológico na escolha, como quarta conclusão, por um lado, os professores portugueses apresentam uma compreensão conjuntural, tendo ela se revelado importante devido à crise econômica pela qual passava seu país, com contenção de custos, inclusive na educação. Por outro, nos posicionamentos dos professores brasileiros, apresentou-se uma compreensão estrutural, pois a gratuidade dos livros do PNLD é custeada pelos impostos. Essas visões são motivadas pelas formas como tem ocorrido o acesso aos livros, seja pela compra direta no mercado ou por meio de um programa de distribuição de livros.

Há, entretanto, a necessidade de se analisar de uma maneira mais ampla essa situação. Escolher os livros em função de seus preços em momentos de crise econômica é conjuntural, dependendo de uma circunstância específica, cujos impactos sobre o orçamento familiar sensibilizam os professores a escolherem um livro mais barato. No entanto os fatores conjunturais não bastam para se enunciar que os livros são mercadorias, pois eles continuarão apresentando um preço mesmo em conjunturas em que não há crise econômica aguda. Assim, eles só podem ser considerados mercadorias desde uma perspectiva estrutural, ou seja, encadeados ao todo da produção social, no contexto de uma sociedade capitalista.

A imbricação entre a cultura escolar, a produção cultural e o mercado indica que, no processo de escolha dos livros didáticos de Física, os professores consideram, no momento da escolha, essas dimensões de modo desigual, promovendo, porém, uma aproximação entre elas em função dos modos como se apropriam dessas obras e das características de seus contextos educacionais.

Essa apropriação, devido à sua complexidade, contrário ao comumente percebido, não ocorre de maneira pontual, em um determinado momento do ano em que as atividades são interrompidas para se analisar as obras, momento que confere aos processos de escolha um certo automatismo que permite aos professores perceberem o que se adéqua ou não ao seu contexto. Configurando-se como um processo de produção de sentidos e significados sobre o papel dos livros didáticos de Física para o processo de ensino-aprendizagem, que toma como pressuposto uma mobilização de conhecimentos e de valores baseados em suas experiências formativas e profissionais, ela ocorre, porém, ao longo do tempo. Assim, os critérios para a escolha dos livros são internalizados em um processo mais amplo, ao longo do tempo, que são, entretanto, mobilizados quando essa atividade for solicitada. 
Neste contexto, ao escolherem seus livros didáticos, os professores de Física realizam uma ponderação complexa entre cultura escolar, produção cultural e mercado. A imbricação desses eixos possibilita compreender que os livros didáticos se constituem em uma totalidade, pois resultam de uma determinada atividade humana orientada a uma finalidade, devendo ser compreendidos em função de suas características específicas.

Assim, a escolha e apropriação dos livros didáticos de Física não se restringe a um determinado momento, de modo pontual e isolado, desenvolvendo-se, ao contrário, por meio de um processo complexo de produção de sentidos e significados, tributário das experiências formativas e profissionais em articulação com os contextos culturais, econômicos e sociais em que os professores e alunos se inserem.

\section{REFERÊNCIAS}

ADORNO, T. W.; HORKHEIMER, M. Dialética do esclarecimento. Rio de Janeiro: Jorge Zahar, 1991.

APPLE, M. Trabalho docente e textos: Economia Política das Relações de Classe e de Gênero em Educação. Porto Alegre: Artes Médicas, 1995.

BARDIN, L. Análise de conteúdo. Lisboa: Edições 70, 1994.

BARRA, V.; LORENZ, K. M. Produção de materiais didáticos de ciências no Brasil, período: 1950 a 1980. Ciência e Cultura, São Paulo, v. 38, n. 12, p. 1970-1983, 1986.

BITTENCOURT, C. M. F. Autores e editores de compêndios e livros de leitura (18101910). Educação e Pesquisa, São Paulo, v. 30, n. 3, p. 475-491, 2004.

BOURDIEU, P. A Economia das Trocas Simbólicas. São Paulo: Perspectiva, 2009.

CASSIANO, C. C. F. O mercado do livro didático no Brasil do século XXI: a entrada do capital espanhol na educação nacional. São Paulo: Editora da Unesp, 2013.

CHERVEL, A. História das disciplinas escolares: reflexões sobre um campo de pesquisa. Teoria e Educação, n. 2, p. 177-229, 1990.

CHOPPIN, A. História dos livros e das edições didáticas: sobre o estado da arte. Revista Educação e Pesquisa, São Paulo, v. 30, n.3, p. 549-566, 2004.

FORQUIN, J.C. Escola e cultura: as bases sociais e epistemológicas do conhecimento escolar. Porto Alegre: Artes Médicas, 1993. 
GARCIA, N. M. D. Livro didático de Física e de Ciências: contribuições das pesquisas para a transformação do ensino. Educar em Revista, v. 28, n. 44, p. 145-163, 2012.

GARCIA, T. M. F. B. Relações de professores e alunos com os livros didáticos de Física. In: SIMPÓSIO NACIONAL DE ENSINO DE FÍSICA, 18., 2009, Vitória, ES. Atas... São Paulo: Sociedade Brasileira de Física, 2016.

LEITE, A. E.; GARCIA, N. M. D.; ROCHA, M. Tendências de pesquisa sobre os livros didáticos de Física. In: GARCIA, N. M. D. (Org.). O livro didático de Física e de Ciências em foco: dez anos de pesquisa. São Paulo: Livraria da Física, 2017. p. 501-515.

LOPES, A. C. Conhecimento escolar: ciência e cotidiano. Rio de Janeiro: Eduerj, 1999.

LORENZ, K. M. Ciência, Educação e Livros Didáticos do Século XIX: os compêndios das Ciências Naturais do Colégio Pedro II. Uberlândia: EDUFU, 2010.

MARX, K. O capital. Livro I, vol. 1. Rio de Janeiro: Civilização Brasileira, 2010.

MEGID NETO, J.; FRACALANZA, H. O Livro Didático de Ciências no Brasil. Campinas: Komedi, 2006.

MUNAKATA, K. O livro didático como mercadoria. Pro-Posições. v. 23, n. 3(69), p. 51-66, 2012.

REIRIS, A. F. La importancia de ser llamado "libro de texto": hegemonía y control del currículum en el aula. Buenos Aires: Miño y Dávila, 2005.

SOUZA, E. L. de; GARCIA, N. M. D. As pesquisas sobre o livro didático de Física e Ciências: temas e perspectivas presentes nos SNEFs. In: GARCIA, N. M. D. (Org.). $O$ livro didático de Física e de Ciências em foco: dez anos de pesquisa. São Paulo: Livraria da Física, 2017. p. 547-557.

WILliAMS, R. Cultura. São Paulo: Paz e Terra, 2000.

WUO, W. A Física e os livros: uma análise do saber físico nos livros didáticos adotados para o ensino médio. São Paulo: EDUC; FAPESP, 2000.

Texto recebido em 04 de maio de 2018. Texto aprovado em 20 de julho de 2018 . 